\title{
Serum immunoglobulin E level of children infected with intestinal parasite in Okada, Nigeria
}

\author{
Alfred Friday Ehiaghe ${ }^{1,2,3,4}$, Edo Dennis Agbonlahor ${ }^{2,5}$, Ositadima Martin Ifeanyichukwu ${ }^{4}$, \\ Digban Kester $^{3}$, Joy Imuetinyan Ehiaghe ${ }^{2,4}$, Faith Efosa Oviasogie ${ }^{6}$
}

\author{
${ }^{1}$ Department of Hematology, College of Health Sciences, Igbinedion University, Okada, Nigeria; \\ *Corresponding Author: fredleo2547@yahoo.com \\ ${ }^{2}$ Lahor Research and Medical Centre, Benin City, Nigeria \\ ${ }^{3}$ Department of Medical Laboratory Science, College of Health Sciences, Igbinedion University, Okada, Nigeria \\ ${ }^{4}$ Department of Medical Laboratory Science, Nnamdi Azikiwe University, Awka, Nigeria \\ ${ }^{5}$ Department of Medical Laboratory Science, College of Health Sciences Niger Delta University, Amassoma, Nigeria \\ ${ }^{6}$ Department of Microbiology, Faculty of Life Sciences, University of Benin, Benin City, Nigeria
}

Received 3 July 2013; revised 1 August 2013; accepted 15 August 2013

Copyright (C) 2013 Friday Alfred Ehiaghe et al. This is an open access article distributed under the Creative Commons Attribution License, which permits unrestricted use, distribution, and reproduction in any medium, provided the original work is properly cited.

\begin{abstract}
Children especially in rural areas of Okada have high rates of intestinal parasitosis with a prevalence of $50 \%$. Stool and blood sample were collected of 334 children which comprised of 152 females and 185 males. Intestinal parasitosis was confirmed by direct smear technique and formol-ether concentration method. Serum IgE level was estimated by ELISA method. It was revealed that children between the ages of 11 15 years had the highest incidence of intestinal parasite in both sex $(73.3 \%$ of the males and $62.5 \%$ of the females). About 2-fold elevation in serum IgE level was demonstrated. Intervention program including early introduction of health education to children is advocated and environmental sanitation should be encouraged.
\end{abstract}

Keywords: IgE; Intestinal Parasitosis; Okada; Rural Children

\section{INTRODUCTION}

Children especially in rural areas have high rates of intestinal parasite infestation due to poor sanitation, contact with contaminated water supply, low level of education and malnutrition [1,2]. Infestation with intestinal parasites is a major health problem in most countries [3]. It is estimated that about 3.5 billion people are infested and 450 million are ill as a result of these infections, and the majority are children [4]. These infections are re- garded as a serious health problem, due to causing iron deficiency anemia, growth retardation in children and other physical and mental health problems [5]. Parasitosis is a major health problem in Nigeria with $50 \%$ prevalence among urban dwellers and $68 \%$ prevalence among rural population [6].

Immunoglobulin $\mathrm{E}$ (IgE) is present in trace amount in normal serum and has very short half-life (2 - 5 days). Its serum concentration is typically increased during infestation with certain parasites $[7,8]$. IgE is one of the five classes of antibodies, like other immunoglobulins. It is produced by B cells and plasma cells. In contrast to other immunoglobulins, the circulating concentration of $\operatorname{IgE}$ is very low because $\mathrm{B}$ cells synthesize it at a very low rate and mast cells, basophils and activated ensinophils bind up most of the circulating IgE [7].

During parasitic infestation, the immune response becomes highly Th2 polarized coincident with the development of the Th2 response. There are notable increases in plasma IgE level and the number of circulating eosinophils, which reflects the production of IL-4 and IL-5, the signature cytokines of Th2 cell helping class switching of B cells of IgE isotype and acting as a growth and survival factor for eosinophils [9]. The present study was conducted to determine the level of $\operatorname{IgE}$ in children living in Okada, Nigeria.

\section{MATERIALS AND METHODS}

Study Area: The study was carried out in the College of Health Science, Department of Hematology, Igbinedion University, Okada. Ethical approval was obtained 
from the IUO ethic committee and informed consent from the parents of the children.

\section{Sample Size:}

The sample size was obtained using this formula

$$
\mathrm{N}=\mathrm{Z}^{2} \times \mathrm{P}(1-\mathrm{P}) / \mathrm{d}^{2}
$$

where:

$\mathrm{N}=$ Minimum sample Size

$\mathrm{D}=$ desired level of significance $(0.05)$

$\mathrm{Z}=$ Confidence interval (1.96)

$\mathrm{P}=$ Prevalence rate $(68 \%)(6)$

Using this formula, the minimum number of sample will be 334 children.

Inclusion criteria: the Inclusion criteria was young children within the age range of 0 - 15 years with no history of any major illness and have not taken a drugs in recent past (2 or 3 weeks before).

Exclusion Criteria: The exclusion criteria were subject above 15 years and a history of an underlying illness.

Duration of Study: This study was carried out between March 2010-March 2011.

\section{Sample Collection and Processing.}

The subjects consist of 334 children which comprises of 152 females and 182 males. The subjects were further divided into two groups. Group one (1) consist of 167 children infested with intestinal parasite confirmed to be positive with direct smear technique and formol-ether concentration method described earlier [11] While Group two (2) consist of 167 children apparently healthy control subjects and faecal samples were confirmed to be negative using the formol ether concentration methods as describe [11].

Various bloods $(2 \mathrm{ml})$ were collected into plain bottles, spin following proper retraction and serum separated. Enzyme linked Immunosorbent Assay (Pharmacia CAP system IgE FEIA < Pharmacia, UPPsala, Sweden) was used in determining the level of $\operatorname{IgE}$ in the serum. The assay system utilizes tow unique antibodies (a mouse monoclonal and a goat polyclonal) directed against distinct antigenic determinants on the IgE molecule. Into the plastic micro titer well water with anti-IgE (Mouse monoclonal) was added test sample/control containing $\operatorname{IgE}$ to form immune complexes. Anti-IgE (goat polyclonal Enzyme-labeled with horseradish peroxidase was added to each well and incubated for 45 minutes at room temperature, the IgE molecule in the sample was sandwiched between the solid phase and enzyme-labeled antibodies. The wells were emptied and washed five times to remove unbound-labeled antibody an enzyme chromogen was added to the wells incubated for 15 minutes at room temperature in the dark, resulting in the development of a blue colour. A stop solution was added to each well and the intensity of the developed yellow colour is directly proportional to the concentration of $\operatorname{IgE}$ in the sample. This was read at $450 \mathrm{~nm}$ wavelength. Awareness Technology Inc. Palm City FL 34991, USA.

\section{Statistical Analysis}

Data was collected using self administered semistructured questionnaire. All numerical results were collated from the groups. Data were presented as mean \pm standard deviation (S.D) and analyzed using one way analysis of variance (ANOVA). Using SPSS version (8.0 $P$ values $\leq 0.05$ were considered significant.

\section{RESULTS}

Our results revealed that children between the age of 11 - 15 had the highest incidence of intestinal parasite in both sex $(73.3 \%$ of the males and $62.5 \%$ of the females) respectively. Subjects between the age bracket of $0-5$ had the lowest incidence of intestinal parasite $(28.1 \%$ of the males and $36.4 \%$ of the females) respectively. The serum IgE level of intestinal parasite infested children increased with the infestation type from single to multiple infestation as compared with the control subjects $(\mathrm{P}<$ $0.05)$.

\section{DISCUSSION}

We observed that $50 \%$ of the populations of children in Okada were infested by intestinal parasites (Tables 1 and 2). This finding is lower than those mentioned by other researcher [6]. These could be attributed to improvement in sanitary situation. The age groups of 11 15 years old were the most infested in our study, these may be due to lack of hand washing practices after detection and their unhygienic feeding habit. This had been reported by other Authors. Seropositivity of intestinal parasites is about $40 \%$ among young people of $6-14$ year old [12]. The high rate of infection among children may be attributed to defection practices of young children and outdoor feeding in higher age groups [13]. Children especially in rural areas have high rates of intestinal parasite infestation due to poor sanitation, contact with contaminated water supply low level of education and malnutrition [1,2].

We observed a surge in the serum IgE level of children infested with the infestation type, from single to multiple infestation as compared with the control $(\mathrm{P}<0.05)$ (Table 3). These may be an adaptive defense mechanism to get rid of the intestinal parasites by the immune system. This finding had been reported by other researchers. The relative abundant circulating $\operatorname{IgE}$ antibodies which are induced by cytokines, such as IL-4 and IL-13, bind the Fc epsilon specific receptors on mast cells, basophiles and eosinophils and trigger the degranulation of these cells, thereby increasing vascular permeability and killing of the parasites [14]. Parasitic infestation can cause a 10 to 100 fold elevation in total serum IgE, these infesta- 
Table 1. Showing age and sex distribution of subjects.

\begin{tabular}{cccccc}
\hline Age Range (yrs) & Subjects & Females & Infested Females & Males & Infested Males \\
\hline $0-5$ & 54 & 22 & $8(36.4)$ & 32 & $9(28.1)$ \\
$6-10$ & 105 & 50 & $20(40)$ & 55 & $25(45.5)$ \\
$11-15$ & 175 & 80 & $50(62.5)$ & 75 & $55(73.3)$ \\
Total & 334 & $152(45.5)$ & $152(45.5)$ & $182(54.5)$ & \\
\hline
\end{tabular}

Table 2. Showing infestation types and intestinal parasite isolated.

\begin{tabular}{ccc}
\hline Infestation Type & Parasite Isolated & Infested Subject \\
\hline Single & A.L & 30 \\
Double & A.L/H.W & 95 \\
Multiple & A.L., H.W., E.h and T.t & 42 \\
& Total & 167 \\
\hline
\end{tabular}

Keys: A.L = Ascaris lumbricoides, H.W = Hookworm, E.h = Entamoeba histolytica, T.t = Trichoris trichiura.

Table 3. Mean \pm standard deviation of serum level of IgE in children infested with intestinal parasites and controls.

\begin{tabular}{cccccc}
\hline \multicolumn{5}{c}{ Infestation type } \\
\hline Parameter & Single & Double & Multiple & Control & P. Values \\
\hline \multirow{2}{*}{$\operatorname{IgE}(\mathrm{IU} / \mathrm{ml})$} & $\mathrm{n}=30$ & $\mathrm{n}=95$ & $\mathrm{n}=42$ & $\mathrm{n}=167$ & \\
& $120 \pm 0.08^{\mathrm{S}}$ & $240 \pm 0.04^{\mathrm{S}}$ & $480 \pm 0.04^{\mathrm{S}}$ & $10 \pm 0.02$ & $\mathrm{P}<0.05$ \\
\hline
\end{tabular}

$\mathrm{S}=$ Statistically significant increase as compared with the control suing Tukey-Krammer multiple comparisons test using SPSS 18.0 (Statistical packages for social Scientist-version 18.0). Statistical program. P values $<0.05$ will be considered significant.

tion not only stimulate the production of specific antiparasite $\operatorname{IgE}$ but also non specifically induce polycolonal IgE synthesis [15]. Serum IgE level increases in atopic diseases, neoplasms, immunodeficeincies, viral and parasitic infections [16,17]. Increased IgE dependent mast cell reaction evolves primarily to localize eosinophils near parasites to enhance anti-parasite effects [7]. Acute infection are seen mostly in children and are associated with a mixed Th1/Th2 cytokine profile and high level of IgE, most of which are parasite specific [18]. Chronic infestation are characterized by a shift of Th2, high level of parasite specific IgE and extremely high level of total IgE, of which only a fraction is parasite specific. An increase in the production of IgE against intestinal parasitic infestation release mediator which stimulate eosinophil differentiation and induce eosinophil cytotoxity [18-20].

\section{CONCLUSION}

About 2-fold elevation in serum IgE level was demonstrated. Intervention program including early introduction of health education to children of the age bracket 6 15 years is advocated and environmental sanitation should be encouraged.

\section{REFERENCES}

[1] Arinola, O.G. and Fawole, O.O. (1995) Prevalence of protozoan and heliminthic infections among different occupational and age group in Iroko Village, Oyo State, Nigeria. Journal of Scientific Engineering Technology, 2, 51-57.

[2] Ramesh, G.N., Malla, N., Raju, G.S., Sehgal, R., Ganguly, N.K., Mahajan, R.C. and Dilawari, J.B. (1991) Epidemiological study of parasitic infestations in lower socioeconomic group in chandigarh (North Indian). Indian Journal of Medical Research, 93, 47-50.

[3] Fabiana, L. and Carolina, M. (2002) Giardiosis in children. BMC Public Health, 2, 5.

[4] World Health Organization (1998) Control of tropical disease. WHO, Geneva.

[5] Evans, A.C. and Stehenson, L.S. (1995) Not by drugs alone: The fight against parasitic helminthus. World Health Forum, 16, 258-261.

[6] Arinola, O.G., Yagub, A. and Rahamon, K.S. (2012) Reduced serum IgE level in Nigerian children with helminthiasis compared with protozoan infection: Implication on 
hygine hypothesis. Annals of Biological Research, 3, 57545757.

[7] Winter, W.E., Hardt, N.S. and Fuhrman, S. (2000) Immunoglobulin E. Importance in parasite infection and hypersensitively response. Archives of Pathology \& Laboratory Medicine, 124, 1382-1385

[8] Arinola, O.G. (2000) Serum total IgE level in healthy children and adults in Ibadan, Nigeria. Tanzania Medical Journal, 23, 9-10.

[9] Pearce, E.J., Kane, M.C. and Sun, J. (2004) Th2 response polarization during infection with the helminth parasite schistosoma mansoni. Immunological Reviews, 201, 117126. doi:10.1111/j.0105-2896.2004.00187.x

[10] Naing, L., Winn, T. and Rush, B.N. (2006) Practical issues in calculating the sample size for prevalence studies. Archives of Orofacial Sciences, 1, 9-14.

[11] Markell, K. and Voge, M. (1998) Medical parasitology. 8th Edition, Saunder Company Publication.

[12] Brage, L.L., Lima, A.A., Sears, C.L. and Newman, R.P. (1996) Seroepidemiology of E. hitoliytical in a slum in northern Brazil. The American Journal of Tropical Medicine and Hygiene, 55, 693-697.

[13] Shammari, S.A., Khoja, T., Khwasky, F.E. and Gad, A. (2001) Intestinal parasitic disease in Riyadh, Saudi Arabia. Prevalence, sociodemographic and environmental associates. Tropical Medicine \& International Health, 6, 184189. doi:10.1046/j.1365-3156.2001.00698.x
[14] Pu, Z. and Francisca, M. (2006) A key antibody in Schistosoma infection. Electronic Journal of Biology, 2, 11-14.

[15] Nagaraji, S., Raghavan, R., Macaden, R. and Kurpad, A.V. (2004) Intestinal parasitic infection and total serum $\operatorname{IgE}$ in asymtoatic adult males in an urban slum and efficacy of antiparasitic therapy. Indian Journal of Medical Microbiology, 22, 56-56.

[16] Koski, K.G. and Scott, M.E. (2001) Gastrointestinal nematodes, nutrition and immunity: Breaking the negative spiral. Annual Review of Nutrition, 21, 297-321. doi:10.1146/annurev.nutr.21.1.297

[17] Chandra, R.K. (1993) Nutrition immunity and infection: Present knowledge and future direction. Lancet, 1, 688691.

[18] Lynch, N.R., Hagel, I.A., Palengie, M.E., Diprisco, M.C., Esandero, J.E., Cozao, L.A., Sandia, J.A., Ferreira, L.J., Botto, C., Perez, M. and Le Souef, P.N. (1998) Relationship between helminthic infection and $\operatorname{IgE}$ response in atopic and nonatopic children in a tropical environment. Journal of Allergy and Clinical Immunology, 101, 217 221. doi:10.1016/S0091-6749(98)70386-0

[19] Gounni, A.S., Lamkhiooued, B. and Ochiai, K. (1994) High-affinity $\operatorname{IgE}$ receptor on eosinophils in involved in defense against parasites. Nature, 367, 183-186. doi: $10.1038 / 367183 \mathrm{a} 0$

[20] Sutton, B.J. and Gould, H.J. (1993) The human IgE network. Nature, 366, 421-428. doi:10.1038/366421a0 